\title{
DOES DUAL SOURCING LOWER PROCUREMENT COSTS?*
}

\author{
ThOMAS P. LYON†
}

\begin{abstract}
U.S. defense policy encourages the use of dual sourcing to reduce government procurement costs, but recent theoretical work raises doubts about the benefits of this policy. I study the determinants of dual sourcing and its effects on government procurement costs using a panel dataset of tactical missiles. I find dual sourcing is not driven by failures to reduce costs; instead, it is used more often after incumbent suppliers demonstrate quality control problems, and in settings where tacit collusion is likely to be difficult. After correcting for selection bias, dual sourcing is found to reduce government procurement costs significantly.
\end{abstract}

\section{INTRODUCTION}

DEFENSE PROCUREMENT INVOLVING HIGH-TECHNOLOGY EQUIPMENT presents an extremely challenging contracting problem. Relatively small production volumes for specialized products often lead to a situation of bilateral monopoly. The nature of future innovations cannot be precisely specified in advance, so contracts are inherently incomplete, and often experience substantial renegotiation over time. ${ }^{1}$ High acquisition costs periodically prompt public outcry.

One response to these challenges has been increased reliance on competition in the procurement process. Defense program managers are 'required by law and regulation to incorporate effective competition in the acquisition of weapon systems, whenever practicable.'2 This is typically accomplished through a bidding competition that splits production between

*I would like to thank the Logistics Management Institute for financial support of this project, and Walt Cooper, Keith Crocker, Robert Feinberg, Jesse Johnson, Bill Rogerson, the editor and three anonymous referees, and seminar participants at the Institute for Defense Analyses, the Rutgers Advanced Workshop on Regulation and Competition, and the Sixth World Congress of the Econometric Society for helpful comments. An earlier version of this paper was circulated under the title 'Competition and Technological Complexity in Procurement: An Empirical Analysis of Dual Sourcing.'

$\dagger$ Author's affiliation: Ross School of Business, University of Michigan, 701 Tappan St., Ann Arbor, Michigan 48109 U.S.A.

e-mail:tplyon@umich.edu

\footnotetext{
${ }^{1}$ Crocker and Reynolds [1993] provide an empirical analysis of contractual incompleteness in defense procurement.

${ }^{2}$ Kratz, Drinnon and Hiller [1984], p. 1-7. These authors, in their handbook for defense program managers, identify a number of specific legislative and regulatory requirements for the use of competition in procurement.
}

(C) Blackwell Publishing Ltd. 2006, 9600 Garsington Road, Oxford OX4 2DQ, UK, and 350 Main Street, Malden, MA 02148, USA. 
two different firms, a practice known as a 'split-award auction' or 'dual sourcing.' (The term 'second sourcing' is used when the incumbent producer is ousted upon poor performance and replaced by an entrant.)

Conventional views about the effective use of dual sourcing have been called into question by recent theoretical work. For example, the Defense Systems Management College, in its handbook for defense program managers, states that, 'If the technology employed in the system is pushing the state-of-the-art, technology transfer is difficult to effect and production competition is difficult to establish. ${ }^{3}$ In contrast, Anton and Yao [1992] use auction theory to argue that "when innovation is a key competitive dimension' this 'increases the attractiveness of a split award auction format to the buyer.' Furthermore, theoretical work by Laffont and Tirole [1993], Riordan and Sappington [1989], and Rogerson [1989] has shown that by reducing suppliers' production rents, the use of a second production source may undermine incentives for $\mathrm{R} \& \mathrm{D}$. These results raise the discomforting possibility that Defense Department pressure to use competition has been counterproductive, and may have actually raised procurement costs or reduced innovation.

Although theory has raised questions about conventional wisdom, our empirical knowledge of the circumstances under which procurement competition is valuable remains remarkably limited. While numerous consultants have performed empirical analyses of this issue, these studies were not grounded in economic theory, and have been roundly criticized by academics for their statistical shortcomings. ${ }^{4}$ This paper aims to do better, using a unique panel dataset comprising 14 tactical missiles over the period 1975-1995 to explore the factors that motivate production competition and the effects of competition on the government's procurement costs. The results should be viewed as preliminary rather than definitive, given the relatively small size of the data set and the complexity of the institutional environment, which includes information asymmetries, agency problems, and political considerations. Nevertheless, I believe the results shed new light on the causes and consequences of dual sourcing, and I hope they will stimulate further research on the topic.

With regard to the causes of dual sourcing, I find no evidence that dual sourcing is used in response to an incumbent producer's failure to control costs. Instead, dual sourcing is used more often after the incumbent experiences quality control problems, thereby giving the buyer additional disciplinary power with respect to product attributes that are difficult to specify in a contract. Dual sourcing is also used more often in circumstances where bidding collusion is less likely — that is, for complex technologies, for

\footnotetext{
${ }^{3}$ Kratz, Drinnon and Hiller [1984], p. 3-5.

${ }^{4}$ Anton and Yao [1990] critique these studies in detail. I discuss their criticisms in section IV below.

(C) Blackwell Publishing Ltd. 2006.
} 
systems that undergo major design modifications, and when there are numerous potential bidders. In addition, dual sourcing is used less often for systems procured under multiyear contracts, suggesting that competition and contractual completeness may be substitutes from the buyer's perspective.

With regard to the consequences of dual sourcing, Defense Department rules do not appear to be raising procurement costs through excessive dual sourcing. Instead, I find that dual sourcing as used in practice reduces procurements costs significantly, apparently spurring efforts at cost control that outweigh any lost economies of scale or learning that result from splitting production across two suppliers. In addition, there is some modest evidence that dual sourcing has the indirect effect of enhancing the competitiveness of subsequent winner-take-all auctions, which may generate additional procurement cost savings.

Overall, these results suggest that dual sourcing plays two economically useful roles: 1) it reduces informational asymmetries between suppliers, which can lower procurement costs by inducing more aggressive bidding, and 2) it gives the buyer more leverage over non-contractible dimensions of product quality. Thus, dual sourcing, properly understood, can be a useful tool in the procurement manager's contractual toolkit.

The remainder of the paper is organized as follows. Section II summarizes the theoretical literature on dual sourcing, and develops a set of testable hypotheses. Section III presents some key features of the institutional environment for procurement, and describes the data used. Section IV discusses some empirical challenges that arise in attempting to assess the effects of dual sourcing, and presents the basic model I estimate. Empirical results are presented in section $\mathrm{V}$, and section VI concludes.

\section{LITERATURE REVIEW}

A relatively small theoretical literature on procurement competition has emerged in recent years. Rooted in agency theory, these papers start from the observation that standard models of regulation and procurement involve a variety of distortions away from the first best due to the agent's possession of private information. Competition is viewed as a means for reducing information rents and improving the efficiency of the procurement process.

Given the complexity of much defense technology, it is helpful to view the procurement process as having a sequence of stages: research and development (R\&D), building an initial prototype and full-scale production. In principle, competition can be introduced at any of these stages and through a variety of contractual mechanisms. For example, the buyer can auction off the right to participate in the initial R\&D tournament, restricting the number of competitors in the tournament to any desired level. Alternatively, the buyer might impose no restrictions on entry into the 
tournament and simply make available to all interested companies a set of design specifications for a desired new product, with the producer of the best prototype being awarded a prize, which might take the form of a contract for full-scale production. Finally, competition at the production stage can take many forms: it may include multiple suppliers from the outset, or may begin with a single supplier who can be replaced or supplemented with other producers should the initial supplier prove unsatisfactory. A rich set of causal linkages is possible across the various stages of the procurement process. For example, if firms anticipate intense competition at the production stage, they may be less willing to invest in $R \& D$ at the outset of the process since the ultimate payoff from successful R\&D is limited. Conversely, if entry into the R\&D tournament is limited, firms may have greater incentives to invest in $R \& D$.

The literature on procurement competition has by no means reached the state where all of the foregoing possibilities are considered and a unique 'best' dynamic procurement policy identified for each possible technological and political circumstance. This should not be terribly surprising given the large range of possible dynamic procurement strategies available. As a result, I do not attempt to identify an optimal procurement strategy, nor to ascertain which of the received theories is 'correct.' At the same time, the theoretical literature on procurement is far more developed than the empirical literature, and I believe it is important to attempt to extract key insights from the theoretical literature and use them as a basis for structuring empirical investigation. Before doing so, several caveats are in order. Each theoretical paper has chosen to study a particular technological and contractual setting, and the results for any particular setting will not necessarily generalize reliably. Furthermore, the objectives of government procurement managers may well include elements that have not been studied carefully in most papers in the procurement literature, including specific performance attributes, reliability, and the option value of having multiple suppliers available in the event of a need to ramp up production rapidly in a crisis.

In light of the limitations of the theoretical literature, my goal in this paper is modest. I do not attempt to test hypotheses regarding R\&D investment by defense contractors, even though the linkage between dual sourcing and $\mathrm{R} \& \mathrm{D}$ investment is a fascinating and important one. Nor do I formally test one paper's theory against another, for the hypotheses I highlight at the end of this section are not mutually exclusive. Instead, I simply try to identify a set of relatively robust ideas about how competition at the production stage (i.e. dual sourcing) affects the government's acquisition costs.

The literature on procurement competition has three primary strands. The first studies auctions for the right to be the sole producer of a particular system. Papers of this type include McAfee and McMillan [1986], Laffont and Tirole [1987, and Riordan and Sappington [1987]. Although these papers generated a number of important insights, they assumed a single 
supplier is guaranteed the full production volume, and thus are not directly suited to the study of competition at the production stage. The second strand of the literature considers the use of second sourcing, i.e. ousting the incumbent and replacing it with a rival firm if incumbent performance is unsatisfactory. This literature includes the models of Anton and Yao [1987], Demski, Sappington and Spiller [1987], Laffont and Tirole [1993, chapter 8], and Riordan and Sappington [1989]. This literature is more helpful for my purposes, but it provides little direct guidance for an empirical analysis of dual sourcing (i.e., the splitting of production volumes between two producers), since the papers do not allow for the possibility that two producers will be used simultaneously; nevertheless, these papers generate some plausible hypotheses regarding the dynamics of the procurement process that should carry over to a setting where production volumes are split. The third strand of the literature explicitly models the possibility of dual sourcing, i.e. splitting production between two competing suppliers; the most prominent paper in this area is Anton and Yao [1992]. This work, however, is conducted in a static setting, so does not generate hypotheses about the dynamics of procurement. Nevertheless, a simple dynamic extension of Anton and Yao [1992] that I discuss below in section II(iii) is quite intuitive, and generates testable hypotheses. In the remainder of this section, I review all three strands of the literature with a focus on the testable hypotheses they produce.

\section{II(i). Bidding for Incentive Contracts}

The theoretical literature applying agency theory to regulation and procurement begins with the seminal work of Baron and Myerson [1982], who studied the problem of a regulator who does not know the costs of the sole supplier with whom he can contract. Under these circumstances, a lowcost firm may have incentives to overstate his costs and induce the regulator to set an unnecessarily high price, thereby allowing the firm to collect an 'information rent.' Baron and Myerson showed how the regulator can design the regulatory contract so as to minimize the 'information rents' the supplier commands. Firms that report lower costs are given higher quantity targets, and in equilibrium earn higher profits. The paper serves as a normative benchmark providing guidance as to what an optimal regulatory policy looks like when the regulator suffers from a severe informational disadvantage, i.e., is totally uninformed about costs.

When several firms are possible candidates to provide the desired good, information rents can be further squeezed by eliciting competitive bids from these firms for the right to be the sole supplier. These bids can be interpreted as including an expected price plus a share of any cost overruns that the firm is willing to bear. Laffont and Tirole [1987] show that in the case of an indivisible project, the contract is awarded to the firm that bids the lowest 
expected price, and that the optimal procurement contract has the same cost-sharing coefficient as would emerge in the non-competitive case. Thus, the bidding competition simply serves to reduce the fixed payment that the buyer must make to the supplier. ${ }^{5}$ A key testable implication is that prices should be lower the greater is the number of bidders for the contract. However, Fullerton and McAfee [1999] show that in procurement settings with an initial stage of $R \& D$ competition, it is often optimal for the buyer to restrict entry into the $R \& D$ tournament to two competitors. By so doing, the buyer reduces the costs of evaluating competing bids and induces the competitors in the tournament to exert maximum effort. Thus, to the extent there is a measurable linkage between the number of initial bidders and ultimate production costs, it may come about by selecting the two most efficient competitors to participate in the R\&D tournament, and then choosing the better of their two prototypes for final production.

\section{II(ii). Second Sourcing}

The initial theoretical papers on second sourcing focused on the use of a second supplier as a means of reducing the information rent of an incumbent producer with an informational advantage over the buyer. ${ }^{6}$ These papers assume the buyer has an initial exclusive supply arrangement with an incumbent supplier. The challenge for the buyer is to design a set of rules governing when the incumbent will be replaced by a rival supplier. The threat of using the second source allows the buyer to induce better performance from the incumbent. Demski, Sappington and Spiller [1987] assume the buyer commits at the outset of the game to a set of conditions (based on the cost reports of the incumbent and, possibly, the potential entrant) under which he will invite the second source to enter, the prices he will pay both suppliers based on all possible cost reports and the quantities each supplier will be asked to produce. Anton and Yao [1987] study a setting in which the buyer has less commitment power: he simply commits to use an auction if he desires to replace the incumbent with a rival supplier. In both models, however, the key testable hypothesis is that a second source is more likely to be used the higher is the incumbent's initial price (or cost report). This is an intuitively appealing result that should be robust to a variety of modeling extensions. In particular, one would expect the same basic intuition to apply if the buyer were shifting only a portion of his purchases to the second source, i.e., engaging in true dual sourcing.

\footnotetext{
${ }^{5}$ Riordan and Sappington [1987] obtain a similar result for the case in which the supplier produces multiple units.

${ }^{6}$ See Anton and Yao [1987] and Demski, Sappington and Spiller [1987]. For example, Anton and Yao [1987] assume the incumbent producer knows a key parameter regarding the learning curve which is unknown to the government or to other producers.

(C) Blackwell Publishing Ltd. 2006.
} 
Riordan and Sappington [1989] present a model of second sourcing that emphasizes the linkage between the R\&D stage and the production stage of the procurement process. In their model, there is an initial bidding stage, followed by an R\&D stage in which the winning bidder makes an investment that enhances the value of the product to the buyer. After observing the quality of the product prototype, the buyer decides whether to award a production contract to the incumbent, or to utilize a second source instead. Although the government can commit to whether or not it will allow a second source to be available at the production stage, it cannot commit to specific production decisions at the R\&D stage. Firms have private information about the cost of production. If the buyer commits to sole sourcing ex ante, then firms have strong incentives to invest in $\mathrm{R} \& \mathrm{D}$, since they are assured of information rents at the production stage if they win the development competition. Competition at the production stage reduces information rents, but as a result it also reduces incentives for R\&D. Riordan and Sappington show that the latter effect often dominates the former, so that the buyer prefers to commit to sole sourcing. They also speculate that splitting production between the two sources may allow the buyer to fine-tune the procurement process and obtain better results than if second sourcing must be an all-or-nothing choice. The authors' key testable result is that the optimal policy for the government is to observe the (unverifiable) quality of a newly developed product, and then select the incumbent developer to produce the product if quality is high (i.e., above a certain threshold), but to oust the incumbent and replace him with a second supplier if quality is low. This result seems robust enough that it should carry through qualitatively to a setting where production is split between two firms ex post.

\section{II(iii). Dual Sourcing}

The third strand of the literature allows for true dual sourcing. In particular, Anton and Yao [1992] provide an insightful comparison between splitaward auctions (in which production is split between two suppliers) and winner-take-all auctions (where all production is performed by a single supplier). The key idea is that when suppliers know each others' costs, they have powerful incentives to collude tacitly in a split-award auction, so this auction format is eschewed by the buyer. When the sellers do not know each others' costs, however, collusion becomes difficult and the split-award format may lead to lower procurement costs than the winner-take-all auction. From an empirical perspective, it is impossible to observe the information possessed by alternative suppliers, so the issue is to identify proxy variables that are correlated with the presence of asymmetric information. Anton and Yao focus on the role of innovation as a proxy: 
In a stable technological environment where long-time competitors are likely to have good information about a competitor's costs, coordination may be easy to achieve, and split award auctions will perform poorly from the perspective of the buyer. However, when innovation is a key competitive dimension, uncertainty introduced by the innovative process makes coordination in split award auctions more difficult and increases the attractiveness of the split award auction format to the buyer. ${ }^{7}$

Thus, for my purposes, the key implication of the model is that dual sourcing is more likely to be used for technologically complex missiles (where there is substantial private information about technologies), especially those without exceptional economies of scale. ${ }^{8}$ A related implication is that dual sourcing is more likely in early periods of production, when less of the incumbent's private information has become available to potential rivals.

While Anton and Yao [1992] lacks the intertemporal structure of some of the other papers cited above, it is straightforward to extrapolate the analysis to a dynamic setting if one is willing to make the assumption that fulfilling on a split award allows the suppliers to become informed about each other's costs. The original paper studies a one-stage auction with and without private information. If costs are private, then the authors show that the buyer may prefer to split the award if the 'dual source efficiency' (DSE) condition holds (it implies that scale economies are not too great); if costs are common knowledge to the bidders, then the winner-take-all auction is preferred. It then follows that the second stage auction should always be a winner-take-all auction and the first stage should be a split-award auction if the DSE condition holds. Indeed, Anton and Yao hint at such a dynamic model: 'In later stages of competition or in environments with stable technology, however, suppliers might best be viewed as having full information about each others' costs. ${ }^{9}$ One rationale for this assumption is that the Department of Defense often goes to considerable lengths to transfer technology to a second source. While the buyer does not observe the suppliers' costs, he does know that the sellers become more fully informed after a split award; there is thus the potential for a dynamic procurement process in which the buyer extracts suppliers' information rents by using a

\footnotetext{
${ }^{7}$ Anton and Yao [1992], p. 700.

${ }^{8}$ An anonymous referee pointed out that when there is much common uncertainty about the ultimate nature of the project, and the technical challenges are substantial, then all bidders may be in roughly comparable states of ignorance, with very little private information of value available to any of them. This is an interesting possibility, but does not fit Anton and Yao [1992], which assumes the bidders learn their private cost parameters before bidding. I am not aware of a paper that models procurement bidding by firms that do not know their costs. At a heuristic level, though, the possibility seems more likely to apply to radically new types of weapons systems, e.g., 'Star Wars' systems for missile defence, than to the development of more familiar defense equipment, such as missiles or the design of new fighter jet engines (the 'Great Engine War') discussed by Anton and Yao.

${ }_{9}^{9}$ Anton and Yao [1992], p. 691. 
split award in one phase of procurement followed by a winner-take-all auction in a later period. The key testable implication of this dynamic extension of the Anton/Yao model is that a phase of dual sourcing is likely to be followed by a winner-take-all auction. ${ }^{10}$

An additional rationale for the use of dual sourcing in early periods of production is suggested by Crocker and Reynolds' [1993] empirical study of Air Force engine procurement contracts. They find that procurement contracts tend to be less complete in a dual sourcing environment, and argue that this is sensible because the presence of alternative suppliers reduces the potential for contractor opportunism. With less concern about opportunism, the buyer can economize on the costs of writing more complete contracts. A complementary interpretation, not mentioned by the authors, is that dual sourcing is particularly valuable in the early stages of development and production, when technological uncertainties make complete contracting particularly difficult. Dual sourcing may serve to discipline contractors when doing so contractually is simply not feasible.

In summary, this section has culled from the literature several testable hypotheses about the use of competition in procurement. The hypotheses are not mutually exclusive, and some are derived by extrapolating from the literature on second sourcing when its insights seem robust to the use of true dual sourcing. They can be organized as follows.

Hypothesis 1: Dual sourcing is more likely to be used after the incumbent charges a high price.

Hypothesis 2: Dual sourcing is more likely to be used after the incumbent producer delivers products with quality defects.

Hypothesis 3: Dual sourcing is more likely for technologically complex missiles without substantial economies of scale or steep learning curves, and in early periods of production.

Hypothesis 4: Dual sourcing is likely to be followed by a winner-take-all auction.

\section{INSTITUTIONAL BACKGROUND AND DATA DESCRIPTION}

This section begins with a brief overview of the missile procurement process used by the Department of Defense. It then provides a description of the data

\footnotetext{
${ }^{10}$ The main technical issue in extending the model to two periods is to show that firms will not veto a split award in the first period by bidding excessively high split prices, which I did in an earlier version of this paper. Indeed, even this issue can be avoided if the buyer knows that Anton and Yao's 'dual source efficiency' condition is met, since he can force a split-award auction by prohibiting the sellers from submitting sole-source bids.
} 
used in the empirical analysis. Short histories of each missile system can be found in the Appendix.

\section{III(i). Procurement Institutions}

The procurement process for a particular missile is under the control of a program manager within the Department of Defense. Program managers have considerable discretion, but are required by law and regulation to use competition whenever it is feasible and effective to do so. They are expected to evaluate feasibility and effectiveness in a detailed, rigorous and quantitative fashion. ${ }^{11}$ Nevertheless, cost control is subsidiary to the goal of producing high-quality, reliable equipment. In addition, ancillary goals such as maintaining a strong defense industrial base may enter the program manager's decisionmaking. Thus, the procurement manager's objective function is multidimensional and difficult to specify precisely.

The program manager's ability to make intertemporal commitments is limited. Obtaining approval for a multiyear contract is not automatic and requires the program manager to meet a set of specific requirements set out by Congress. In my sample, only nine system-years of procurement were conducted under multiyear contracts. For the typical missile, then, decisions are made on a year-by-year basis with no guarantees as to future government behavior. This makes the system-year the natural unit of observation. ${ }^{12}$

Three procurement 'regimes' are observed in the sample considered here: 1) sole sourcing (no competition), 2) dual sourcing (split award auctions), and 3) winner-take-all (WTA) auctions. With one exception, ${ }^{13}$ all missiles in my sample start their production runs with a period of non-competitive sole sourcing. This gives the initial manufacturer a period of time to recoup development costs and to work out technical bugs within the system. Some missiles then go on to a period of dual sourcing in which production is split between two manufacturers. While it is theoretically possible for one bidder in a split-award auction to end up with all of the production, this is never observed within my sample. Finally, dual sourcing may be followed by a WTA auction, with production being handled once again by a single manufacturer. This is sometimes referred to as a 'program buy out,' and program managers are expected to employ this tool only at the end of a production run. ${ }^{14}$ In my sample, there are no cases of WTA auctions without prior periods of dual sourcing.

\footnotetext{
${ }^{11}$ See Kratz, Drinnon and Hiller [1984], p. i.

${ }^{12}$ This reality is reflected in the procurement handbook prepared by the Defense Systems Management College, which emphasizes 'continuous production competition,' in which 'the split may be changed through a series of reprocurements.' See Kratz, Drinnon, and Hiller [1984], p. 1-14.

${ }_{13}$ The AMRAAM missile system was dual sourced for its entire production history.

${ }^{14}$ Kratz, Drinnon and Hiller [1984], p. 14-16. 


\section{III(ii). Data Description}

The dataset I study includes all missile systems reported in the U.S. Defense Department's Selected Acquisition Reports (SAR) for the period 19751995. By law, these reports must be submitted to Congress each year by the Secretary of Defense, and must include all 'major defense acquisition programs.' Such a program is defined as 'a Department of Defense acquisition program that is not a highly sensitive classified program (as determined by the Secretary of Defense) and (1) that is designated by the Secretary of Defense as a major defense acquisition program; or (2) that is estimated by the Secretary of Defense to require an eventual total expenditure for research, development, test, and evaluation of more than $\$ 300,000,000$ (based on fiscal year 1990 constant dollars) or an eventual total expenditure for procurement of more than $\$ 1,800,000,000$ (based on fiscal year 1990 constant dollars). ${ }^{15}$

The variables used and summary statistics are presented in Table I. Fourteen different missile systems are examined. The total number of observations (system-years) is 175 , so the average number of years/system is 12.5. The number of system-years of initial sole source procurement was 107 , the number of system-years of dual sourcing was 55, and of winner-take-all auctions was 13 . The number of periods under multiyear contract was nine: Stinger was under a multiyear contract from 1988-1991, and Patriot from 1987-1991. ${ }^{16}$ Two missiles (Tomahawk and Stinger) experienced major design changes during the production period. The number of potential bidders was 2 in 1975, and was between 4 and 8 in all other years. ${ }^{17}$ Brief histories of each missile system can be found in the Appendix.

The dependent variable on which the price analysis focuses is total 'flyaway cost' per missile, which is the price paid by the government per missile. This is appropriate for studying how government procurement costs are affected by the use of dual sourcing. Nevertheless, there are three limitations to this measure which should be kept in mind when interpreting results. First, as in most other empirical work on the learning curve, e.g. Lieberman [1984], I am unable to obtain data on actual production costs, so

${ }^{15}$ U.S. Code Title 10, Subtitle A, Part IV, Chapter 144, Section 2430, paragraph (a). According to U.S. Code Title 10, Subtitle A, Part IV, Chapter 144, Section 2432, paragraph (b), a program may be excluded from the SAR if: '(i) the program has not entered system development and demonstration; (ii) a reasonable cost estimate has not been established for such program; and (iii) the system configuration for such program is not well defined.' Since I am interested in programs that have entered the production phase of procurement, these considerations are not relevant for my purposes.

${ }^{16}$ Before Defense Department procurement officials can enter into a multiyear contract, they must somehow establish that the multiyear contract will produce savings of at least the Congressionally mandated minimum level of $15 \%$.

${ }^{17}$ The number of bidders was determined through the combined judgments of several experts familiar with the missile industry. More details are available in Cooper et al. [1997]. 
TABLE I

SUMmary STATISTICS

\begin{tabular}{|c|c|c|c|c|c|}
\hline Variable & Definition & Mean & Std. Dev. & Min & $\operatorname{Max}$ \\
\hline LNFLY & Log of Unit Cost (\$Million) & -0.978 & 1.576 & -4.300 & 1.770 \\
\hline LNCUMQ & $\begin{array}{l}\text { Log of Cumulative } \\
\text { Production Quantity }\end{array}$ & 8.144 & 1.858 & 3.757 & 12.337 \\
\hline LNQTY & $\begin{array}{l}\text { Log of Current } \\
\text { Production Quantity }\end{array}$ & 6.742 & 1.522 & 1.792 & 10.212 \\
\hline DESGNDUM & $\begin{array}{l}\text { Dummy Variable }=1 \\
\text { if Major Redesign }\end{array}$ & 0.079 & 0.270 & 0 & 1 \\
\hline MULTIDUM & $\begin{array}{l}\text { Dummy Variable }=1 \\
\text { if Multiyear Contract Used }\end{array}$ & 0.051 & 0.222 & 0 & 1 \\
\hline DUALDUM & $\begin{array}{l}\text { Dummy Variable = } 1 \\
\text { if Dual Sourcing Used }\end{array}$ & 0.3143 & 0.466 & 0 & 1 \\
\hline WTADUM & $\begin{array}{l}\text { Dummy Variable }=1 \\
\text { if Winner-take-all Auction } \\
\text { Used after Dual Sourcing }\end{array}$ & 0.08 & 0.272 & 0 & 1 \\
\hline NUMBID & Number of Potential Bidders & 6.890 & 1.193 & 2 & 8 \\
\hline COMPLEX & $\begin{array}{l}\text { Dummy Variable }=1 \\
\text { if Technology is Complex }\end{array}$ & 0.5 & 0.501 & 0 & 1 \\
\hline LENGTH & Years of Procurement & 12.5 & 3.627 & 7 & 20 \\
\hline FYR & Fiscal Year & 1986.173 & 4.607 & 1975 & 1995 \\
\hline PERIOD & Period of Production & 10.5 & 5.777 & 1 & 20 \\
\hline QTOGO & Total Future Production & 9777.868 & 27108.06 & 0 & 225639 \\
\hline FLYRATLG & $\begin{array}{l}\text { Ratio of Previous Period's Cost } \\
\text { to Initial Period Cost }\end{array}$ & 0.397 & 0.269 & 0.054 & 1.046 \\
\hline PROBLEMS & Cumulative Problems Noted in AW\&ST & 2.189 & 3.253 & 0 & 14 \\
\hline
\end{tabular}

focus instead on prices. ${ }^{18}$ Second, total flyaway cost incorporates both fixed and variable costs. The SAR system also reports 'recurring' flyaway cost, which is intended to track only variable costs of production. However, sources familiar with the data indicate that the accounting criteria for separating out recurring costs are vague, and that total flyaway cost is the more reliable measure. Third, the SAR data show total procurement costs each year for a given missile system, along with total units produced, but the division of production between suppliers is not available. Thus, the data aggregate across both suppliers during periods of dual sourcing. This means that estimates of economies of scale or rates of learning are weighted averages of the performance of the two suppliers.

The two basic production variables that drive costs are cumulative production (to track learning effects) and scale (to track scale economies). Cumulative production was measured using the 'lot midpoint' for each year. This is the quantity at which learning effects would be precisely equal to their average over the entire production lot for that year. ${ }^{19}$ The natural logarithm

\footnotetext{
${ }^{18}$ Lieberman [1984] provides a discussion of conditions under which price data can be reliably used to estimate learning curves.

${ }^{19}$ The standard expression for the learning curve is $C=a Q(t)^{b}$, where $C$ is average cost and $Q(t)$ is cumulative production through period $t$. Total cost of production during period $t$ is then $T C(t)=\int_{Q(t-1)}^{Q(t)} a Q(x)^{b} d x$. We seek a midpoint $M$ such that $a M^{b}=T C(t)$. Solving for $M$ gives $M=\left[Q(t)^{b+1}-Q(t-1)^{b+1}\right]^{1 / b}$.

(C) Blackwell Publishing Ltd. 2006.
} 


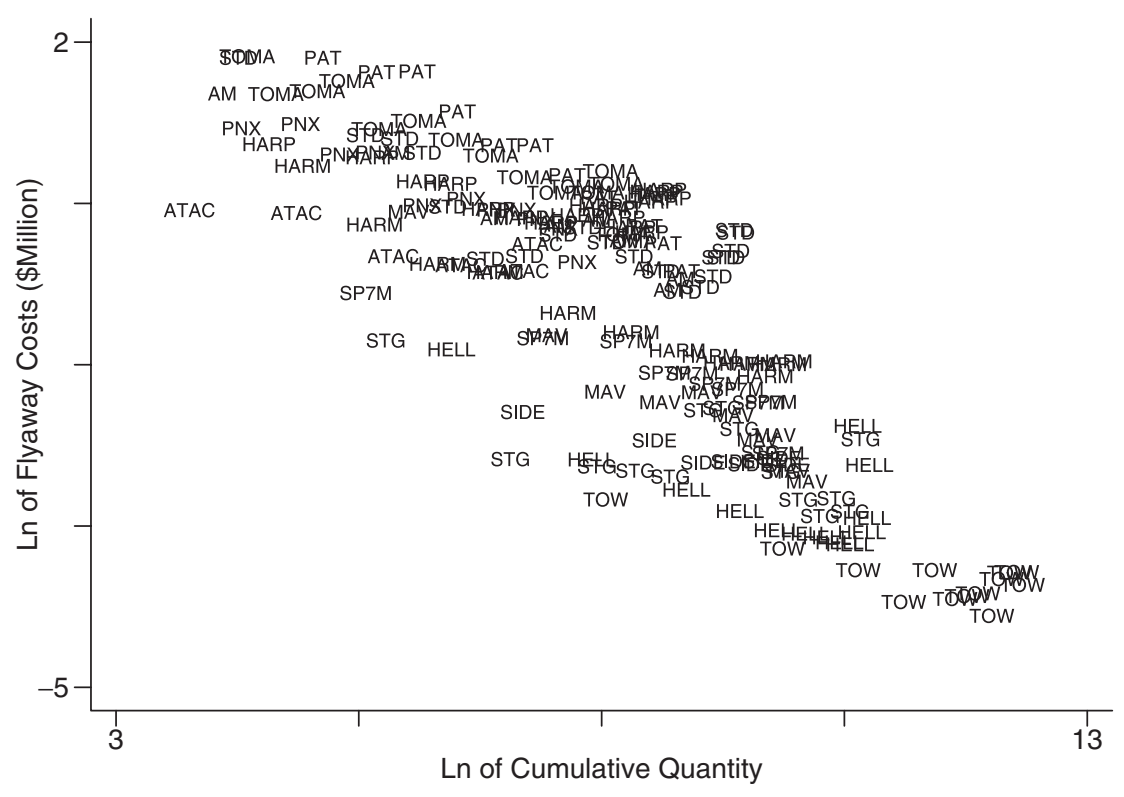

Figure 1

Flyaway Costs vs. Cumulative Production for Full Sample

of the cost and production data was employed to simplify the estimation process. A plot of the natural log of flyaway costs vs. the natural log of cumulative production is presented in Figure 1 for the sample as a whole, with each datapoint identified by an abbreviation for the missile's name. A strong linear pattern is readily identified. The individual graphs for each missile separately are presented in Figure 2. Note that the production quantities include both U.S. and foreign missile sales, in order to avoid biases that would occur from using U.S. sales alone.

Technological complexity plays an important role in the analysis, particularly that of the missiles' guidance and control systems. The simplest missile in the dataset is the TOW 2, a vehicle-mounted anti-tank missile guided by an operator who keeps the target centered in a telescopic sight. Moving the sight sends electronic signals through two wires to the missile to correct its flight. At the other extreme are Patriot and Tomahawk, 'fire-andforget' missiles with highly sophisticated guidance and control systems that pushed the state of the art when they were fielded. ${ }^{20}$ The missiles are ranked in order of the complexity of their guidance and control systems in Table II.

\footnotetext{
${ }^{20}$ See Cooper et al. [1997], chapter 4, for further description of each missile's technological complexity. 

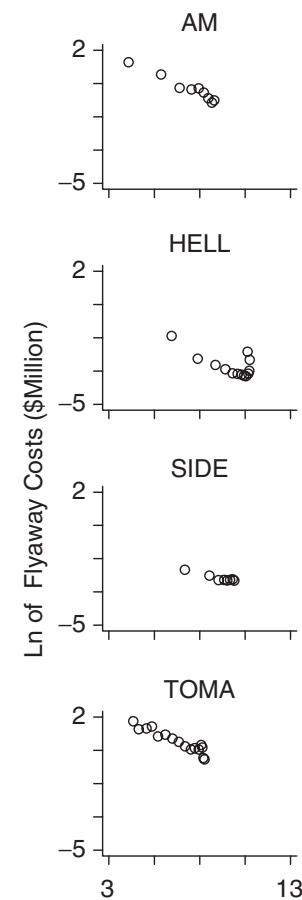

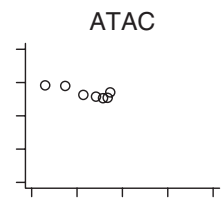

MAV

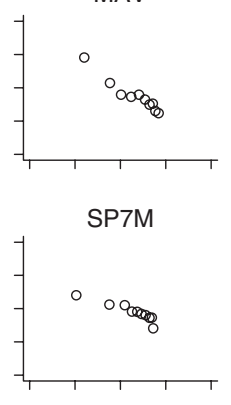

TOW

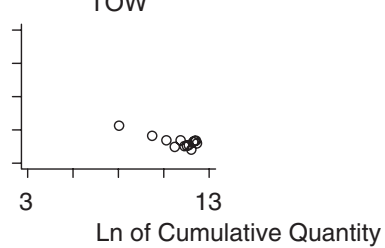

HARM

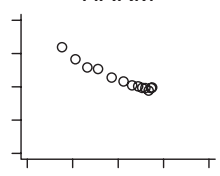

PAT

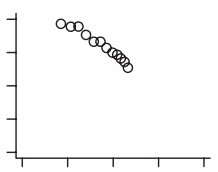

STD

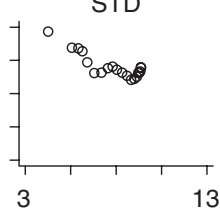

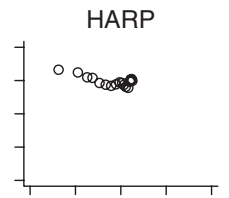

PNX

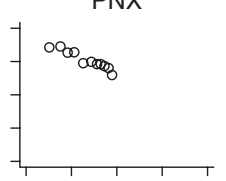

STG

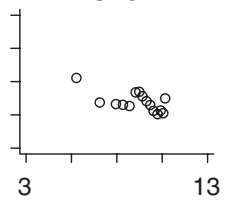

Figure 2

Flyaway Costs vs. Cumulative Production by Missile

The key policy variable for this analysis is the decision regarding how many producers to use. Table III provides a history for all the missiles, showing all periods for which SAR data were available, and indicating for each missile in each year whether production was procured through a solesource, dual-source, or WTA process. ${ }^{21,22}$ Recall that hypothesis (4)

${ }^{21}$ In some cases, it was necessary to make judgement calls regarding when the transition to dual sourcing began. Take the case of the Phoenix missile, for example, as described by Cooper et al. [1997]. Hughes Aircraft began production as the sole source in 1980, and enjoyed a monopoly position for six years. In 1986, Raytheon obtained a contract to produce 10 'learning units,' in 1987 Raytheon produced 56 'qualification units,' and in 1988 Raytheon built 180 units under a 'directed contract.' Finally, in 1989, Raytheon competed in a split-award auction against Hughes. I have chosen to classify the years 1986-1988 as dual sourced. On one hand, this is problematic, since there was no formal split-award auction and thus no chance for bidding collusion. On the other hand, classifying these years as sole sourced would arguably be worse, since Hughes was effectively on notice that it faced competition and could no longer take its monopoly position for granted.

${ }^{22}$ A remarkably careful reader might note that there are only 174 entries in Table III, while the text states there are 175 observations. The reason is that the Harpoon data include an 'extra' period with date 'FY7T' between 'FY76' and 'FY77.' 
TABLE II

Technological Characteristics of Missile Systems

\begin{tabular}{|c|c|c|c|}
\hline System & Type & Guidance & Complexity \\
\hline Patriot & Surface-to-air & Track-via-missile & Complex \\
\hline Tomahawk & $\begin{array}{l}\text { Surface-to-surface, } \\
\text { submarine-to-surface }\end{array}$ & $\begin{array}{l}\text { Inertial navigation, } \\
\text { TERCOM } \\
\text { updates, digital scene } \\
\text { matching }\end{array}$ & Complex \\
\hline AMRAAM & Air-to-air & Active radar & Complex \\
\hline Harpoon & $\begin{array}{l}\text { Air-to-surface, surface-to- } \\
\text { surface, submarine-to-surface }\end{array}$ & $\begin{array}{l}\text { Active radar, attitude } \\
\text { reference assembly }\end{array}$ & Complex \\
\hline Phoenix & Air-to-air & $\begin{array}{l}\text { Semi-active radar in } \\
\text { midcourse; active radar in } \\
\text { terminal phase }\end{array}$ & Complex \\
\hline $\begin{array}{l}\text { Standard } \\
\text { Missile } 2\end{array}$ & Surface-to-air & Semi-active radar & Complex \\
\hline $\begin{array}{l}\text { Sparrow AIM/ } \\
\text { RIM-7M }\end{array}$ & $\begin{array}{l}\text { Air-to-air, surface-to-air, } \\
\text { surface-to-surface }\end{array}$ & Semi-active radar & Complex \\
\hline ATACMS & Surface-to-surface & Ring laser gyro & Simple \\
\hline HARM & Air-to-ground & Radio frequency homing & Simple \\
\hline$I^{2} R$ Maverick & Air-to-surface & Infrared homing & Simple \\
\hline Hellfire & Air-to-ground & Semi-active laser seeking & Simple \\
\hline $\begin{array}{l}\text { Sidewinder } \\
\text { AIM-9M }\end{array}$ & Air-to-air & Infrared homing & Simple \\
\hline Stinger & Surface-to-air & Infrared homing & Simple \\
\hline TOW2 & Surface-to-surface & Wire guided & Simple \\
\hline
\end{tabular}

predicts that dual sourcing will be followed by a WTA auction. Table III generally supports this hypothesis. Nine missile systems experienced dual sourcing at some point during their production histories, of which five eventually switched to a winner-take-all auction. However, this simple comparison is a bit misleading since two of the nine systems were idiosyncratic cases. Standard Missile 2 was an anomalous case, since the two producers, Hughes and Raytheon, merged their production operations for this missile at the end of its production run in 1995, making a WTA auction infeasible. In addition, AMRAAM was a peculiar case in a number of respects, including its use of dual sourcing in all periods and its very high rate of quality control problems. Thus, of the remaining seven systems, five switched to a winner-take-all auction. The other two systems - Sidewinder and Sparrow-were dual sourced up through their final production periods. ${ }^{23}$

Quality control problems are a potentially important factor affecting the decision to utilize dual sourcing. I proxied for this variable by performing a search of LEXIS/NEXIS by missile, using the keywords 'problem,' 'delays,' 'defects,' and 'malfunction.' I found a total of 43 stories reporting the use of

\footnotetext{
${ }^{23}$ This may have been particularly sensible in the case of Sparrow, since it is the only missile that actually demonstrated negative economies of scale at the individual system level, as shown below in Table V.
} 


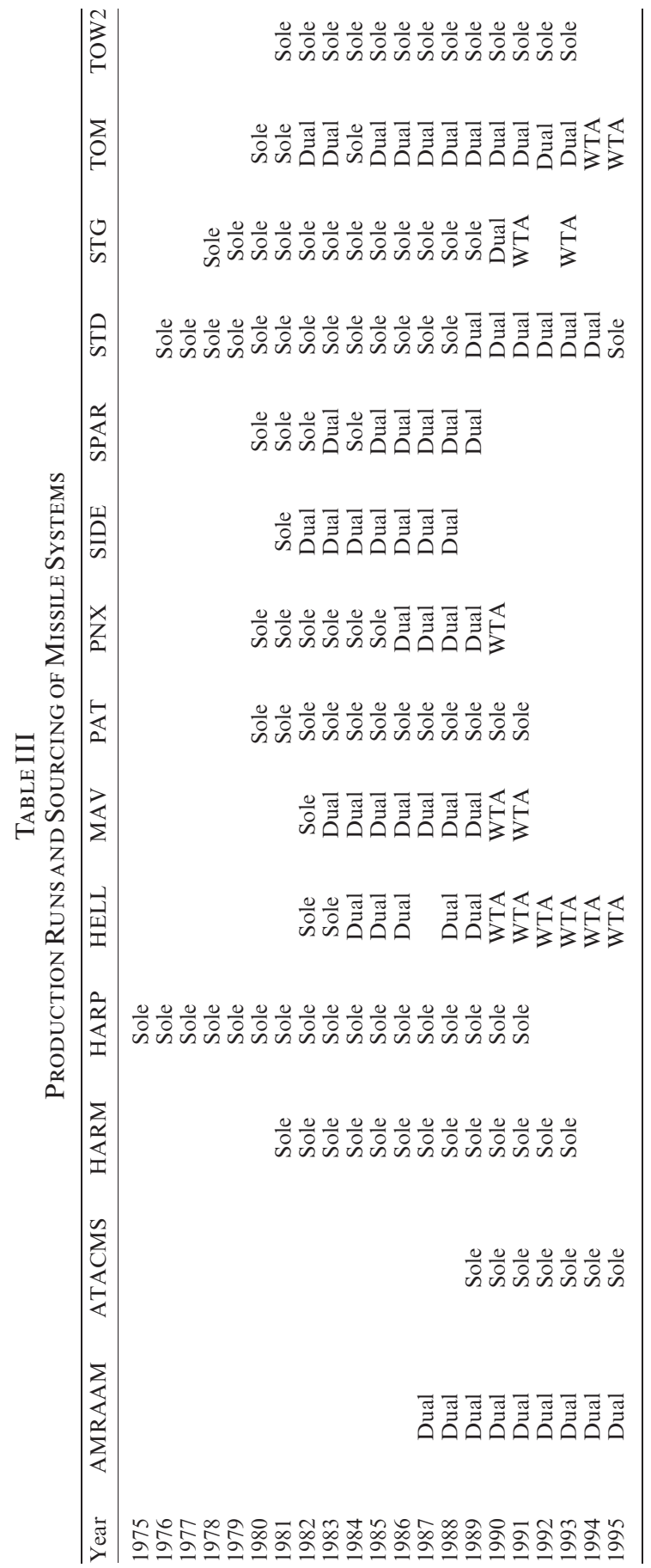


TABLE IV

Reported Quality Control Problems for Complex and Simple Missiles

(Results excluding AMRAAM in parentheses)

\begin{tabular}{lcc}
\hline & Complex & Simple \\
\hline Number of Reported Problems & $35(21)$ & 8 \\
Number of Observations & $96(87)$ & 79 \\
Problems/System-Year & $0.36(.24)$ & 0.10 \\
\hline
\end{tabular}

TABLEV

System-LeVel Estimates of Scale Economies and Learning

\begin{tabular}{llccccc}
\hline System & Complexity & $\begin{array}{c}\text { Scale } \\
\text { Economics } \\
\text { Slope }\end{array}$ & $\begin{array}{c}\text { Learning } \\
\text { Curve Slope }\end{array}$ & $\begin{array}{c}\text { Total Quality } \\
\text { Problems }\end{array}$ & $\begin{array}{c}\text { Procurement } \\
\text { Mode }\end{array}$ & $\begin{array}{c}\text { Number of } \\
\text { Years Dual } \\
\text { Sourced }\end{array}$ \\
\hline TOW2 & Simple & .79 & .90 & 0 & Sole only & 0 \\
ATACMS & Simple & .82 & .95 & 0 & Sole only & 0 \\
HARM & Simple & .87 & .82 & 1 & Sole only & 0 \\
Patriot & Complex & .84 & .72 & 4 & Sole only & 0 \\
Harpoon & Complex & .96 & .86 & 2 & Sole only & 0 \\
AVERAGE & & .86 & .85 & 1.4 & & \\
Phoenix & Complex & .79 & .88 & 7 & Switch & 4 \\
Hellfire & Simple & .79 & .79 & 0 & Switch & 5 \\
Standard & Complex & .80 & .90 & 1 & Switch & 6 \\
$I^{2} R$ Maverick & Simple & .82 & .74 & 7 & Switch & 7 \\
Stinger & Simple & .83 & .86 & 0 & Switch & 1 \\
Sidewinder & Simple & .93 & .86 & 0 & Switch & 7 \\
Tomahawk & Complex & .97 & .77 & 6 & Switch & 11 \\
Sparrow & Complex & 1.23 & .76 & 1 & Switch & 6 \\
AVERAGE & & .82 & .90 & 2.75 & & 6 \\
AMRAAM & Complex & .75 & .96 & 14 & Dual only & 9 \\
\hline
\end{tabular}

one or more of these terms for a missile in my sample. ${ }^{24}$ Table IV summarizes this data for complex and simple missiles separately, while Table V presents it for each missile system separately. Interestingly, complex missiles are more than three times as likely to suffer quality control problems than are simple missiles. Five missile systems accounted for $88 \%$ of the reported problems: AMRAAM (14 reported problems), Maverick (7), Patriot (4), Phoenix (7), and Tomahawk (6). All of these, with the exception of Maverick, are complex missile systems. Three of these systems (Maverick, Phoenix, and Tomahawk) switched from sole sourcing to dual sourcing as the number of problems grew. Patriot was sole sourced from the beginning and never switched to dual sourcing, while AMRAAM was dual sourced from the beginning and never switched to sole sourcing. AMRAAM is somewhat of an outlier, but even excluding it, however, complex missiles are more than twice as likely to suffer problems than are simple missiles.

\footnotetext{
${ }^{24} \mathrm{I}$ read each of the articles individually and attempted to winnow down the list to avoid duplicative reports on the same problems. 
A number of quantitative characteristics of the various missile systems are presented in Table V. Included in the table are system-by-system estimates of the slope of the learning curve and the 'slope' of the average cost curve, ${ }^{25}$ along with the total number of reported quality problems and the number of years of dual sourcing for each missile. Each missile is categorized according to whether it is always sole sourced, always dual sourced, or switches between procurement regimes; within each category, missiles are ranked by the extent of scale economies they exhibit. Recall that hypothesis (2) predicts dual-sourcing to be more common for missiles with demonstrated quality control problems. Consistent with the hypothesis, Table V shows that missile systems that switched procurement regimes had many more quality control problems than missiles that were sole sourced. This simple comparison leaves open the question of whether dual sourcing is used to discipline sole suppliers who experience quality control problems, or whether dual sourcing causes quality control problems, a question that will be considered further in the empirical analysis below in section V. In at least one instance, though, the trade press reported that the switch from sole to dual sourcing was a direct result of quality problems:

The U.S. Navy will seek a second production source for the Hughes AIM54C Phoenix air-to-air missile after a second round of inspections determined there were serious quality control problems in producing the missiles. The decision for a second production source was made after a Navy team at Hughes' Tucson, Ariz., production line recently dismantled and inspected two missiles and found that problems in producibility and quality control were continuing. ${ }^{26}$

\section{THE EMPIRICAL MODEL}

This section presents the empirical model I estimate. Before specifying the empirical model, however, I discuss prior empirical work and some of the methodological issues it raises.

Not surprisingly, the Department of Defense has long been interested in the role of competition in the procurement process, and has sponsored a number of empirical studies to assess the effects of dual sourcing on price competition. Anton and Yao [1990] review nine such analyses. The general conclusions from this work are: 1) The sole-source contract price declines over time; 2) It is unclear whether the learning curve is steeper under competition; 3) When there is a switch from sole-sourcing to dual-sourcing,

\footnotetext{
${ }^{25}$ The slope coefficients reported in Table $\mathrm{V}$ can be interpreted as the result of estimating equation (4) below on a system-by-system basis.

26 'Navy Will Seek Second Source for Phoenix,' Aviation Week and Space Technology, July 16, 1984, p. 20.

(C) Blackwell Publishing Ltd. 2006.
} 
the first competitive price is generally below the last sole-source price; 4) Electronics programs benefit more from competition than other programs, e.g., missiles or torpedoes/bombs; and 5) The second source won most of the winner-take-all competitions, but experienced (quality) problems in the post-competitive phase. All but one of the studies found that competition reduced costs.

Anton and Yao are generally quite critical of these empirical studies, for a variety of reasons. Some studies make obvious errors such as failing to incorporate learning effects, scale economies, or inflation. Most of the studies estimate learning effects for each program separately, and thus lack enough data points to test interesting hypotheses. Some studies fail to include data for sole-source periods prior to dual sourcing. All but one of the studies fail to analyze programs that only used sole-sourcing. As a result, the samples may be biased because the choice to go to dual sourcing may be conditioned upon high costs by the initial producer. In addition to the foregoing flaws, most prior empirical papers were written before the development of recent advances in contract theory and auction theory, so they were not guided by very sophisticated theoretical hypotheses.

The limitations of the existing empirical literature have several important implications for this paper. First, technological complexity (and the attendant asymmetric information across rival firms) may have important effects on the performance of dual sourcing, and should be controlled for empirically. Second, the use of panel data on a set of related procurement programs over time should allow for improvements over previous empirical work. Third, it is important to avoid selection bias by including both missiles with and without periods of dual sourcing. Fourth, interaction effects between contractual completeness and the use of dual sourcing should offer additional insight into the importance of complexity and uncertainty in procurement management. These four implications all figure importantly in the analysis to follow.

The central empirical problem examined here involves estimating the effect of dual sourcing on government procurement costs. However, the use of dual sourcing for a particular missile is not exogenously imposed. Instead, procurement officers decide whether to use dual sourcing based on past supplier performance, technological factors, and other issues as discussed above in section III(i). Thus, OLS estimates of the effects of dual sourcing will be biased. It is necessary to correct explicitly for the selection bias introduced by the choice process of the procurement officer. This is precisely the problem studied by Heckman [1978], so I use a Heckman-style selection model to account for the endogenous determination of the decision to dual source a particular missile. The empirical model can be written as

$$
\ln Y_{i t}=\alpha_{i}+\beta \ln X_{i t}+\gamma D_{i t}\left(X_{i t}, Y_{i t-1}\right)+\varepsilon_{i t},
$$

(C) Blackwell Publishing Ltd. 2006. 


$$
\begin{aligned}
& \Delta_{i t}=\theta^{\prime} Z_{i t}+\mu_{i t}, \\
& D_{i t}=\left\{\begin{array}{cc}
1 & \text { if } \Delta_{i t}>0 \\
0 & \text { otherwise. }
\end{array} .\right.
\end{aligned}
$$

In equation (1), $Y_{i t}$ is the unit 'flyaway' cost for the $i^{t h}$ system in year $t, \alpha_{i}$ is a system-specific fixed effect, $X_{i t}$ is a set of independent variables, $D_{i t}$ is a dummy variable that captures the decision to use dual sources (i.e., to conduct a split-award auction), and $\varepsilon_{i t}$ is an error term. In equation (2), the variable $\Delta_{i t}$ is a latent variable which measures the net benefit to the buyer of using dual sourcing instead of sole sourcing for the $i^{t h}$ missile and the $t^{t h}$ period, $\theta$ is a vector of coefficients, $Z_{i t}$ is a vector of independent variables, and $\mu_{i t}$ is an error term. The latent variable $\Delta_{i t}$ generates the dual sourcing decision variable $D_{i t}$ via equation (3).

The standard assumptions in the literature are that $\varepsilon_{i t}$ and $\mu_{i t}$ are independent and identically distributed draws from a bivariate normal distribution with mean zero, variances $\sigma_{1}^{2}$ and $\sigma_{2}^{2}$, and covariance $\sigma_{12}{ }^{27}$ The variance of $\mu_{i t}$ is typically not identified and is normalized to one. For present purposes, these assumptions may be overly restrictive. In particular, it is possible that unobserved missile-specific effects mean that while error terms are independent across missiles, they are not independent over time for a given missile. To allow for this possibility, I employ a robust standard error estimation known as the 'cluster' estimator. ${ }^{28}$ Kézdi [2002] shows that this estimator is consistent in panel estimations with fixed effects; more importantly, he uses Monte Carlo simulations to demonstrate that the cluster estimator behaves well in finite samples.

Given the importance of learning-by-doing and scale economies in producing sophisticated weapons systems, these two variables are key elements of $X_{i t}$ The specific form of (1) that I estimate is

$$
\begin{aligned}
\ln Y_{i t}= & \alpha_{i}+\beta_{1} L N C U M Q_{i t}+\beta_{2} L N Q T Y_{i t}+\beta_{3} \text { WTADUM } M_{i t} \\
& +\beta_{4} \text { DESGNDUM } M_{i t}+\beta_{5} \text { MULTIDUM } M_{i t}+\gamma_{1} D_{i t}+\varepsilon_{i t}
\end{aligned}
$$

where $L N C U M Q_{i t}$ represents the log of cumulative production of system $i$ through period $t$, and $L N Q T Y_{i t}$ is current production of system $i$ in period $t$ alone, $W T A D U M_{i t}$ is a dummy variable indicating a winner-take-all auction after a phase of dual sourcing, $D E S G D U M_{i t}$ is a dummy variable indicating whether a major design change was implemented for system $i$ in period $t$, and MULTIDUM $M_{i t}$ is a dummy variable indicating whether a multiyear contract was in use for system $i$ in period $t$. The parameters $\beta_{1}$ and $\beta_{2}$ are often referred

\footnotetext{
${ }^{27}$ If $\sigma_{12}=0$ then $D_{i t}$ is not endogenous and OLS estimates are not biased. I discuss this issue further in section $\mathrm{V}$.

${ }^{28}$ For a discussion of applications of the cluster estimator, see Wooldridge [2003]. 
to in the literature as the 'slope' of the learning curve and the average cost curve, respectively.

Similarly, the specific form of equations (2) and (3) that I estimate is

$$
\begin{aligned}
D_{i t}= & \theta_{1} \text { LNCUMQ }_{i t}+\theta_{2} \text { LNQTY }_{i t}+\theta_{3} \text { DESGNDUM }_{i t} \\
& +\theta_{4} \text { MULTIDUM } M_{i t}+\theta_{5} \text { FLYRATLG }_{i t}+\theta_{6} \text { NUMBID }_{t} \\
& +\theta_{7} \text { PERIOD }_{i t}+\theta_{8} \text { FYR }_{i t}+\theta_{9} \text { COMPLEX }_{i}+\theta_{10} \text { LENGTH }_{i} \\
& +\theta_{11} \text { QTOGO }_{i t}+\theta_{12} \text { PROBLEMS }_{i t}+\mu_{i t}
\end{aligned}
$$

where $N U M B I D_{t}$ is the number of potential bidders to produce a system in period $t, P E R I O D_{i t}=t$ indicates that system $i$ is in its $t^{t h}$ year of production, $F Y R_{i t}$ is the fiscal year when system $i$ was in its $t^{\text {th }}$ period of production, COMPLEX $X_{i}$ is a dummy variable indicating whether a particular system is technologically complex or not, $L E N G T H_{i}$ indicates the total number of periods of production for system $i$ over its production life, $Q T O G O_{i t}$ is the number of units of system $i$ that will be produced over the remainder of its production life, FLYRATLG $G_{i t}$ is the ratio of system i's flyaway costs in period $t-1$ to its flyaway costs in period 1 , and $P R O B L E M S_{i t}$ is the cumulative number of quality assurance problems experienced by missile $i$ up until period $t .^{29}$ Note that the use of variables such as $L E N G T H_{i}$ and $Q T O G O_{i t}$ implies an assumption that the agents in the model have rational expectations about the future.

It is perhaps worth noting that this model produces estimates of the effect of dual sourcing on missiles that are selected for competition. In the language of Heckman and Vytlacil [2004], this is the effect of 'treatment on the treated.' The results cannot be extrapolated to infer the results of policy experiments, such as what would happen if Defense Department policy were to require all procurement managers to make use of dual sourcing. However, the estimates do allow me to assess the internal consistency of existing guidelines for the use of dual sourcing, in the sense of investigating whether

\footnotetext{
${ }^{29}$ The motivation for selecting these particular variables comes from both the theoretical literature discussed in section II and from the conventional wisdom about when dual sourcing is likely to be efficacious. The monograph Establishing Competitive Production Sources: A Handbook for Program Managers, published by the Defense Systems Management College, provides a list of variables that form a 'Preliminary Screen of Programs for Competition,' indicating that dual sourcing is more promising when: total quantity (captured by the variable $Q T O G O_{i t}$ ) is larger; production duration (captured by $L E N G T H_{i}$ ) is greater; the progress curve (captured by FLYRATLG $G_{i t}$ ) is flatter; the technical complexity (captured by COMPLEX) is more modest; and contract complexity (captured by MULTIDUM $M_{i t}$, which also serves as an independent variable in estimating flyaway costs) is more modest. In addition, I include a measure of the number of potential bidders who have the technological capability to serve as a second source, $N U M B I D_{t}$, reasoning that dual sourcing is more likely when the number of alternative bidders is greater.
}

(C) Blackwell Publishing Ltd. 2006. 
TABLEVI

Maximum Likelihood Estimates of Log of Flyaway Costs

\begin{tabular}{lcc}
\hline & $\begin{array}{c}(1) \\
\text { V.E. with } \\
\text { AR1 errors }\end{array}$ & $\begin{array}{c}(2) \\
\text { Heckman with } \\
\text { Clustering }\end{array}$ \\
\hline LNCUMQ & $-.272^{a}$ & $-.262^{a}$ \\
LNQTY & $(-2.92)$ & $(-4.20)$ \\
& $-.330^{a}$ & $-.329^{a}$ \\
DESGNDUM & $(-9.14)$ & $(-6.50)$ \\
MULTIDUM & $.328^{a}$ & $.480^{a}$ \\
DUALDUM & $(2.48)$ & $(3.08)$ \\
& $-.248^{b}$ & $\left(-.391^{a}\right.$ \\
WTADUM & $(-2.27)$ & $-.227^{a}$ \\
& .046 & $(-2.86)$ \\
Constant & $(.71)$ & -.133 \\
& -.133 & $(-1.46)$ \\
Overall R-squared & $(-1.27)$ & $3.448^{a}$ \\
Fvalue & .259 & $(15.71)$ \\
Observations & $(.53)$ & 161 \\
\hline
\end{tabular}

${ }^{a}$ Significant beyond the $1 \%$ level.

${ }^{b}$ Significant beyond the $5 \%$ level.

cSignificant beyond the $10 \%$ level.

these guidelines have promoted excessive use of procurement competition, as suggested by some of the recent theoretical work discussed in section II.

\section{EMPIRICAL RESULTS}

The empirical results are presented in two steps. I begin with econometric estimates of the extent to which dual sourcing lowers procurement costs, and then turn to the determinants of the government's decision regarding when to use dual-sourcing.

\section{V(i). Price Improvement under Dual Sourcing}

This section addresses the primary empirical question of interest: does dual sourcing lower procurement costs? Table VI presents estimates of flyaway costs, each of them with missile fixed effects. ${ }^{30}$

Estimation (1) presents the results of an OLS panel estimation that treats $D_{i t}$ as a predetermined variable, allowing for the error terms to take the

\footnotetext{
${ }^{30}$ A Hausman test rejects the hypothesis that the missile system effects $\alpha_{i}$ are uncorrelated with the regressors $X_{i t}$, and hence indicates that the fixed effects estimator is preferred to the random effects estimator. 
form $\varepsilon_{i t}=\rho \varepsilon_{i t-1}+\eta_{i t}{ }^{31}$ The results do not take into account the selection process by which procurement managers determine which missiles to subject to dual sourcing, but are presented as a benchmark against which to compare the results corrected for selection bias. The results for estimation (1) indicate that both learning and scale economies are very important determinants (statistically and economically) of a missile system's price to the government. The 'slope' of the learning curve is $72.8 \%$, meaning that a doubling of cumulative production is associated with a $27.2 \%$ reduction in unit price; the estimate is highly significant. Scale economies are evident and highly significant as well; a doubling of per-period production reduces the unit price of the average missile by $33.0 \%$. Major design changes are associated with substantial and statistically significant increases in procurement prices for simple missiles, as is to be expected. The coefficient on DESGNDUM in estimation (1) is .328, so a major design change raises unit flyaway cost by a factor of $e^{.328}=1.388$, almost a $40 \%$ increase. Multiyear contracting, in contrast, appears to generate efficiencies. It reduces flyaway costs by a factor of $e^{-.248}=.78$ implying that costs fall by $22 \%$ with multiyear contracting. This level exceeds the Congressionally mandated minimum of $15 \%$ savings from a multiyear contract, and suggests that the typical lack of commitment power on the part of Department of Defense procurement officials may impose significant costs on the procurement process.

Estimation (1) shows dual sourcing to have a small and statistically insignificant effect on procurement costs. Along with the immediate effects of dual sourcing, however, one must also consider the impact of using a winner-take-all auction after a number of periods of dual sourcing, as suggested by Hypothesis 4. Although the coefficient on WTADUM is negative, it is not statistically significant at standard levels.

Estimation (2) presents results of estimating equation (1) using a Heckman-style selection model in which the decision to dual source a given missile in a given year is determined endogenously via equation (3). The estimated covariance of the error terms for the two equations, $\sigma_{12}$, is .843 with standard error .086 , and a likelihood ratio test of the hypothesis that $\sigma_{12}=0$ can be rejected with greater than $99 \%$ confidence. This confirms that the selection model is an appropriate specification, and that the OLS coefficient on the dual-sourcing dummy is biased. As in estimation (1), economies of learning and of scale are large and highly significant. The magnitudes of the coefficients on these variables change very little as a result

\footnotetext{
${ }^{31}$ For this estimation, the modified Durbin-Watson statistic proposed by Bhargava et al. [1982] is equal to 1.053-low enough to reject the hypothesis of serial independence of the error terms.
} 
of correcting for selection bias. Design changes are associated with greater cost increases in the selection model, with the increase roughly $61.5 \%$. In contrast, the selection model finds multiyear contracting to be more effective at reducing costs than in estimation (1), with an average reduction of $32.3 \%$.

The most notable change resulting from use of the selection model is with respect to the effects of dual sourcing. Now dual sourcing is found to have a large and highly significant effect on procurement costs. In particular, it reduces costs by $20.4 \%$ on average for those missile systems to which it is applied. The coefficient on the winner-take-all dummy is -.133, indicating a cost reduction of $12.5 \%$ from the use of this procurement tool. The effect is only significant at the $14.5 \%$ confidence level, however. Nevertheless, these results reject the notion that Defense Department guidelines have led to such excessive use of dual sourcing that cost savings are not being achieved. Procurement managers appear to be utilizing dual sourcing in circumstances where it has a good chance of controlling procurement costs.

\section{V(ii). The Dual-Sourcing Decision}

This section explores the determinants of the government's decision to use dual-sourcing for a particular missile in a particular year, which allows me to shed some light on Hypotheses (1)-(3).

Table VII presents the results of estimating equation (3) simultaneously with equation (1). Hypothesis (1), that dual sourcing is more likely when the incumbent fails to reduce price over time (i.e., when FLYRATLG is high), receives little support, since the coefficient on FLYRATLG is not statistically significant. Hypothesis (2), that dual sourcing is more likely after the incumbent experiences quality assurance problems, receives significant support in estimation (1). The coefficient on PROBLEMS is positive and significant at better than the $10 \%$ level.

Hypothesis (3), which predicts that dual sourcing is more likely for complex missiles and in early periods of production, receives mixed empirical support. The coefficient on the dummy variable COMPLEX is large and significant at the $1 \%$ level, but the coefficient on PERIOD is insignificant. Similarly, the coefficient on $Q T O G O$ is statistically insignificant. The coefficient on length of contract was negative and significant.

In addition to testing these hypotheses from the literature, several other results emerge from estimation (1). Neither cumulative production nor current production have significant effects on the decision to use dual sourcing. However, dual sourcing was significantly more likely after a major design change, which is consistent with the notion that dual sourcing is more valuable when potential competitors are uncertain about each others' costs. Multiyear contracts are considerably more complete than those that are renegotiated annually, and one might expect that dual sourcing is less 
TABLEVII

MaXimum Likelihood Estimates of Determinants of the Dual-Sourcing Decision (t-statistics in parentheses)

\begin{tabular}{lc}
\hline Variable & Heckman with Clustering \\
\hline Flyratlg & -1.603 \\
& $(-1.46)$ \\
Problems & $0.108^{c}$ \\
& $(1.71)$ \\
Complex & $1.325^{a}$ \\
Period & $(3.01)$ \\
& 0.018 \\
Lncumq & $(0.12)$ \\
Lnqty & 0.215 \\
& $(0.62)$ \\
Desgndum & 0.247 \\
Multidum & $(1.04)$ \\
Numbid & $.941^{a}$ \\
& $(2.57)$ \\
Length & $-1.574^{b}$ \\
QTOGO & $(-2.17)$ \\
Constant & $0.420^{a}$ \\
Number of observations & $(3.01)$ \\
\end{tabular}

${ }^{\text {a }}$ Significant beyond the $1 \%$ level.

${ }^{\mathrm{b}}$ Significant beyond the $5 \%$ level.

${ }^{\mathrm{c}}$ Significant beyond the $10 \%$ level.

valuable in such a setting. Indeed, the negative coefficient on MULTIDUM (significant at the $11 \%$ level) indicates that dual sourcing is $22 \%$ less likely when multiyear contracting is employed. Finally, dual sourcing was more likely the greater the number of potential bidders.

Overall, there is little evidence that procurement officials employ dual sourcing in response to strictly cost-based grounds. Neither cumulative nor current output had significant effects on the likelihood of dual sourcing, nor did a missile's failure to reduce costs over time. Furthermore, neither the length of the contract nor the expected quantity to be procured affected the dual sourcing decision. Instead, the factors that motivate dual sourcing are related to contracting difficulties: complex missiles with a history of quality control problems were more likely to be dual sourced, especially if there was a larger number of potential bidders available. Since complexity and quality are difficult variables on which to contract, dual sourcing may be a convenient tool for disciplining procurement problems on these dimensions. The contracting perspective is further supported by the observation that dual sourcing and multiyear contracting appear to be substitutes rather than complements. This result is complementary to that of Crocker and Reynolds 
[1993], who find that contracts tend to be less complete when dual sourcing is used. $^{32}$

\section{CONCLUSIONS}

Defense procurement policy presses program officers to use dual sourcing whenever possible, out of a belief that competition will reduce procurement costs to the government. The recent theoretical literature on dual sourcing raises doubts about the efficacy of this policy, and suggests that procurement policies stressing competition could actually backfire and raise costs. This study is the first to test the effects of dual-sourcing policy in the context of modern industrial organization theory. A review of the theoretical literature generated a number of theoretical hypotheses for empirical testing, which I evaluated using both results for individual missile systems and results from the full panel of data.

My empirical results indicate that dual sourcing is being used in such a way that it does successfully lower procurement costs. Indeed, dual sourcing appears to produce procurement cost savings on the order of $20 \%$ for those missiles to which the policy is applied. The benefits of dual sourcing appear to be two-fold: 1) it reduces informational asymmetries between suppliers, thereby inducing more aggressive bidding in subsequent auctions, and 2) it gives the buyer more leverage over non-contractible dimensions of product quality.

Information asymmetries between suppliers are likely to be greatest for complex missile systems in early periods of production. My results show that dual sourcing is used more often in exactly these situations, where technological uncertainty reduces the ability of bidders to coordinate their bids to achieve monopolistic prices in split-award auctions. Furthermore, assuming dual sourcing facilitates knowledge exchange between suppliers, as Defense Department policy seems to intend, then a simple extension of Anton and Yao [1992] predicts that a phase of dual sourcing should be followed by a switch to a winner-take-all auction, and this is indeed frequently observed in the data. Although the results are not statistically significant at standard levels, my empirical results suggest that a winnertake-all auction after a period of dual sourcing may produce additional procurement cost savings to the government.

When missile quality is non-contractible, the model of Riordan and Sappington [1989] predicts that buyers will bring in a second supplier when the incumbent experiences quality control problems. I find support for this prediction: defense program managers resort to dual sourcing significantly more often when the incumbent has experienced significant problems with

\footnotetext{
${ }^{32}$ This result must be treated with caution, however, as the results for this variable are only significant at the $11 \%$ level in estimation (1), and do not appear robust across estimations (2) and (3). This is perhaps not too surprising, given that there are only two examples of multiyear contracting in the sample.
} 
quality control. In addition, program managers appear to treat multiyear contracts and dual sourcing as substitutes, providing further evidence that contractual incompleteness is an important reason for the use of dual sourcing.

The results reported here focus on the price benefits of competition and do not attempt to measure contractors' innovation investments, or how they are affected by competition. Rogerson [1989] emphasizes that Defense Department policy has traditionally provided incentives for innovation by allowing firms to collect economic profits during the production phase of procurement. Introducing competition in production reduces those profits and threatens to weaken incentives for research and development. Future empirical research on the connection between dual sourcing of production and innovation performance at the research and development phase of procurement would be an extremely valuable complement to the work reported here.

\section{APPENDIX}

This Appendix provides brief overviews of the missile systems studied here, including technological features and procurement history. Further details can be found in Cooper et al. [1997].

$A M R A A M$ is a supersonic, all-weather, short-to-medium range, fire-and-forget missile used by fighter pilots to destroy enemy aircraft. The Hughes Missile Systems Company developed AMRAAM, but production has been divided between Hughes and Raytheon since initial production began in FY 1987. Since FY 1989 production has been split about evenly between the two producers, with about $51 \%$ awarded to Hughes. AMRAAM is an unusual missile system in at least two key respects. First, the use of dual sourcing from the initial year onwards is highly unusual in procurement. Second, as detailed in the data description section, AMRAAM has suffered from far more reported quality control problems than any other missile.

$A T A C M S$ is a ground-launched missile system consisting of a surface-to-surface guided missile with an anti-personnel, anti-material warhead. It employs a ring laser gyro for its guidance system. Loral Vought Systems developed ATACMS and has been the sole source producer.

HARM is a supersonic, air-to-ground missile for use against land or sea-based radar emitters associated with enemy air defenses. The missile locks onto and homes in on radar emissions on a wide range of frequencies. Numerous different aircraft can launch HARM. Texas Instruments is the developer and sole source supplier. In FY 1990, the Defense Department purchased 100 low-cost radar seekers from Loral Corporation, in expectation that Loral would compete with Texas Instruments in FY 1992 and beyond. However, reductions in planned procurement quantities made dual-sourcing impractical, and these plans were canceled.

Harpoon is an all-weather, sea-skimming, anti-ship missile with a range in excess of 50 miles. The Harpoon can be launched from aircraft, surface vessels, and submarines. It possesses a sophisticated active radar seeker as part of its guidance system. McDonnell Douglas Missile Systems Company is the developer and sole source producer for Harpoon. 
Hellfire is an air-to-ground missile system designed to defeat individual hardpoint targets while minimizing exposure of the delivery vehicle to enemy fire. Its guidance system is a semi-active laser seeking system. For the first two years of production, the Army bought seekers from Martin Marietta Orlando Aerospace and provided them to Rockwell International Corporation for assembly into the missile system. Full-scale dual sourcing between Martin Marietta and Rockwell occurred between FY 1984 and FY 1989. A winner-take-all competition was held in FY 1990, with all production being awarded to Rockwell.

Imaging Infrared $\left(I^{2} R\right)$ Maverick is an air-to-surface missile launched from tactical aircraft against a broad array of armor and ground targets. It can be used both day and night, and in adverse weather conditions. The missile was developed by the Hughes Missile Systems Company, which was the sole production source in FY 1982. Beginning in FY 1983, Raytheon Corporation was selected as a second source, and was awarded a small-scale 'qualification' contract. In FY 1987, a full-scale competitive split award auction was held, with Hughes winning approximately $2 / 3$ of the production quantity. Dual sourcing continued through FY 1989. In FY 1990, a winner-take-all competition was held, with Hughes emerging the winner. This was thought to be the final contract for the Maverick, but when Operation Desert Storm substantially depleted stocks of the missile, a second winner-take-all competition was held in FY 1990, with Raytheon winning the contract.

Patriot is a land mobile, surface-to-air guided missile that provides medium-to-high altitude, long-range air defense for ground combat forces. Raytheon Company is the developer and sole source producer, with support from Lockheed Martin for some components. From FY 1987 through FY 1991, Patriot was produced under a multiyear contract. The Army claims the multiyear contract saved $12 \%$ of costs relative to a series of five single-year contracts.

Phoenix is a supersonic, long range, air-to-air missile with semi-active radar guidance during midcourse, switching to active radar guidance in the terminal phase. Hughes Aircraft Company developed the missile, and was the sole producer through FY 1985. Beginning in FY 1986, the Air Force began the process of preparing a second source, Raytheon Company, for production. Raytheon received a contract for 10 'learning units' in FY 1986, 56 'qualification units' in FY 1987, and 180 units under a 'directed contract' in FY 1988. The first full-scale split-award auction was held in FY 1989, with Raytheon winning slightly over half the production quantity. Hughes won a winner-take-all competition in FY 1990, the final year of production.

Sidewinder is a supersonic missile for use in short-range, air-to-air combat against high- or low-speed enemy aircraft. It uses passive infrared target detection, proportional navigation guidance, and an active optical target detector. The original Sidewinder missile was developed in the 1950's, but the version considered here (the AIM-9M) was developed by Raytheon and first produced in FY 1981. Dual sourcing was employed from FY 1982 through the end of production in FY 1988, with Ford Aerospace and Communications Corporation the second source.

Sparrow is a semi-active, radar-guided, medium-range, supersonic air-to-air and surface-to-air/surface-to-surface missile that is used against a variety of targets under all weather conditions. The original Sparrow was developed in 1946. However, the ' $M$ ' model considered here did not begin production until FY 1980. Initial production contracts were sole sourced, but dual sourcing between Raytheon and General 
Dynamics began in FY 1983, and was continued again in FY 1985 through the end of production in FY 1989.

Standard Missile 2 is a modular, all-weather, medium and long range, surface-to-air missile used by a variety of naval craft. It has a semi-active radar guidance system. Standard Missile 2 was developed by the Pomona Division of General Dynamics Corporation, which was the sole source through FY 1988. Beginning in FY 1989, Raytheon was awarded a production contract in a dual source competition; Raytheon continued to capture part of split awards up through FY 1994. In 1992, Hughes Aircraft Company purchased the General Dynamics Missile Systems Division, and consolidated all missile production at its production facility in Tucson, Arizona. Hughes continued to compete with Raytheon in split award auctions. In 1995, Hughes and Raytheon formed a new company, the Standard Missile Company, to consolidate their work on the missile. This consolidation was supported by the Navy due to a force downsizing and a reduction in the number of Standard Missiles required.

Stinger is a shoulder-fired, man-portable, air defense missile using optical aiming and passive infrared homing guidance. Versions of it are also deployed on a variety of vehicles, including helicopters, ships, and tanks. Stinger was developed by General Dynamics Corporation, which was the sole source producer from FY 1978 through FY 1989. General Dynamics received a multiyear contract from FY 1988 through FY 1991. Raytheon was awarded a contract as a second source in FY 1990, but lost a winnertake-all competition to General Dynamics in FY 1991. Hughes Aircraft purchased General Dynamics Missile Systems in 1992.

Tomahawk is a multipurpose cruise missile that can be outfitted with conventional or nuclear warheads. It is capable of hitting targets with an accuracy of plus or minus 25 feet over distances of 250 miles or more. Tomahawk can be launched from submarines, surface vessels, and mobile ground launchers. General Dynamics Corporation developed the Tomahawk, and was the sole producer in FY 1980 and FY 1981. Beginning in FY 1982, McDonnell Douglas Corporation was qualified as the second source for Tomahawk, and received small contracts in FY 1982 and FY 1983. Full scale dual sourcing began in FY 1985, and McDonnell Douglas won 40\% of that year's total production. Dual sourcing continued through FY 1993. Hughes Aircraft acquired General Dynamics' missile production in 1992, and in FY 1994 and FY 1995 Hughes was awarded the full production quantity.

TOW 2 is a vehicle-mounted or crew-portable, heavy anti-tank assault weapon that can also be used against field fortifications. It has been installed on a variety of vehicles including helicopters, jeeps and tanks. After launch, the missile must be guided by an operator who keeps the target centered in a telescopic sight. Hughes Aircraft developed the TOW 2, and has been the sole source producer. McDonnell Douglas was qualified as a second source in FY 1989, but dual-sourcing plans were abandoned before any competitions were held.

\section{REFERENCES}

Anton, J. J. and Yao, D. A., 1987, 'Second Sourcing and the Experience Curve: Price Competition in Defense Procurement,' RAND Journal of Economics, 18, pp. 57-76.

Anton, J. J. and Yao, D. A., 1990, 'Measuring the Effectiveness of Competition in Defense Procurement: A Survey of the Empirical Literature,' Journal of Policy Analysis and Management, 9, pp. 60-79. 
Anton, J. J. and Yao, D. A., 1992, 'Coordination in Split Award Auctions,' Quarterly Journal of Economics, 107, pp. 681-707.

Aviation Week and Space Technology, 1984, 'Navy Will Seek Second Source for Phoenix,' July 16, p. 20.

Baron, D. and Myerson, R., 1982, 'Regulating a Monopolist with Unknown Costs,' Econometrica, 50, pp. 911-930.

Bhargava, A.; Franzini, L. and Narendranathan, W., 1982, 'Serial Correlation and the Fixed Effects Model,' Review of Economic Studies, 49, pp. 533-549.

Cooper, W. R.; Domin, J. S.; Lyon, T. P.; Feinberg, R. M.; Johnson, J. P. and Lee, D. A., 1997, Empirical Analysis of Cost Progress Curves: Tactical Missiles (Logistics Management Institute, McLean, Virginia).

Crocker, K. J. and Reynolds, K. J., 1993, 'The Efficiency of Incomplete Contracts: An Empirical Analysis of Air Force Engine Procurement,' RAND Journal of Economics, 24, pp. 126-146.

Demski, J. S.; Sappington, D. E. M. and Spiller, P. T., 1987, 'Managing Supplier Switching,' RAND Journal of Economics, 18, pp. 77-97.

Fullerton, R. L. and McAfee, R. P., 1999, 'Auctioning Entry into Tournaments,' Journal of Political Economy, 107, pp. 573-605.

Heckman, J. J., 1978, 'Dummy Endogenous Variables in a Simultaneous Equation System,' Econometrica, 46, pp. 931-959.

Heckman, J. J. and Vytlacil, E., 2005, 'Structural Equations, Treatment Effects and Econometric Policy Evaluation,' Econometrica, 73, pp. 669-738.

Kézdi, G., 2002. 'Robust Standard Error Estimation in Fixed-Effects Panel Models,' working paper, University of Michigan.

Kratz, L. A.; Drinnon, J. W. and Hiller, J. R., 1984, Establishing Competitive Production Sources: A Handbook for Program Managers (Defense Systems Management College, Fort Belvoir, Virginia).

Laffont, J. J. and Tirole, J., 1987, 'Auctioning Incentive Contracts,' Journal of Political Economy, 95, pp. 921-937.

Laffont, J. J. and Tirole, J., 1988, 'Repeated Auctions of Incentive Contracts, Investment and Bidding Parity,' RAND Journal of Economics, 19, pp. 516-537.

Laffont, J. J. and Tirole, J., 1993, A Theory of Incentives in Procurement and Regulation (The MIT Press, Cambridge, Massachusetts).

Lieberman, M. B., 1984, 'The Learning Curve and Pricing in the Chemical Processing Industries,' RAND Journal of Economics, 15, pp. 213-228.

McAfee, R. P. and McMillan, J., 1986, 'Bidding for Contracts: A Principal-Agent Analysis,' Rand Journal of Economics, 17, pp. 326-338.

McGuire, T. and Riordan, M. H., 1995, 'Incomplete Information and Optimal Market Structure: Public Purchases from Private Providers,' Journal of Public Economics, 56, pp. $125-141$.

Riordan, M. H. and Sappington, D. E. M., 1987, 'Awarding Monopoly Franchises,' American Economic Review, 77, pp. 375-387.

Riordan, M. H. and Sappington, D. E. M., 1989, 'Second Sourcing,' RAND Journal of Economics, 20, pp. 41-58.

Rob, R., 1986, 'The Design of Procurement Contracts,' American Economic Review, 76, pp. 378-389.

Rogerson, W. P., 1989, 'Profit Regulation of Defense Contractors and Prizes for Innovation,' Journal of Political Economy, 97, pp. 1284-1305.

Wooldridge, J. M., 2003, 'Cluster-Sample Methods in Applied Econometrics,' American Economic Review, 93, pp. 133-138. 